\title{
Efficient adsorption capability of banana and cassava biochar for malachite green: Removal process and mechanism exploration
}

\author{
Hua Deng ${ }^{1,2}$, Ya Fen $\mathrm{Li}^{1,2}$, Shu Qi Tao ${ }^{1,2}$, An Yu $\mathrm{Li}^{1,2}$, Qiu Yan $\mathrm{Li}^{1,2}$, Le Ning $\mathrm{Hu}^{1,2^{\dagger}}$ \\ ${ }^{1}$ Guangxi Normal University Key Laboratory of Karst Ecology and Environmental Change, Guilin, Guangxi 541004, China \\ ${ }^{2}$ College of Environment and Resources, Guangxi Normal University, Guilin, Guangxi 541004, China
}

\begin{abstract}
In this study, banana biochar (BB) and cassava biochar (CB) were roasted in a tube furnace at $400^{\circ} \mathrm{C}$ for $2 \mathrm{~h}$, and their adsorption effects on malachite green (MG) were studied. The removal of MG with respect to the solution concentration and reaction time was also investigated. The results show that the optimal amount of biochar is $2 \mathrm{~g} / \mathrm{L}$. Studies of the adsorption kinetics and adsorption isotherms show that the pseudo-second-order kinetics can most accurately reflect the adsorption process. Freundlich model fits the experimental data well. The theoretical saturated adsorption capacities of BB and CB are $1,092.80 \mathrm{mg} / \mathrm{g}$ and $261.42 \mathrm{mg} / \mathrm{g}$, respectively. SEM-EDS, TGA, BET, FTIR, XRD, element analysis and other characterization techniques were used to explore the adsorption mechanism. Based on the characterization results, it is speculated that the adsorption of $\mathrm{BB}$ and $\mathrm{CB}$ for MG mainly includes chemical adsorption and physical adsorption.
\end{abstract}

Keywords: Adsorption, Adsorption mechanisms, Biochar, Biomass materials, Malachite Green

\section{Introduction}

With economic development and industrialization, the types and output of synthetic dyes have rapidly increased. According to statistics, there are more than 10,000 types of dyes worldwide, and the annual output exceeds 700,000 tons [1]. The data show that during processing and discharge, dyes cause serious pollution. In the processing stage, the dye output may decrease by $30 \%$, and the amount of dye that is directly discharged into wastewater without treatment can reach 10-15\% [2]. Most dyes have high colour, toxicity and carcinogenicity, which make them harmful to human health. In addition, dye wastewater will destroy the aquatic ecosystem, affect the chemical oxygen demand (COD) and biological oxygen demand (BOD) in water, and reduce the light transmission capacity of water [3].

Malachite green (MG) is a common cationic dye and easily soluble in water. MG can kill fungi, bacteria and parasites in water and dye materials such as textiles, wool, and paper products [4]. Therefore, it is widely used in the fishery and textile industry. MG is also a highly toxic triphenylmethane (TMP) teratogen and carcinogen and has been classified into the second category of dangerous goods. However, many countries continue using MG

This is an Open Access article distributed under the terms of the Creative Commons Attribution Non-Commercial License (http://creativecommons.org/licenses/by-nc/3.0/) which permits unrestricted non-commercial use, distribution, and reproduction in any medium, provided the original work is properly cited.

Copyright (C) 2022 Korean Society of Environmental Engineers in large quantities because of its low cost and fast results [5]. Therefore, many scholars have begun to focus on the removal of MG in wastewater.

At present, the number of treatment technologies for MG in wastewater is continuously increasing, including coagulation, precipitation, catalysis, photocatalysis, and biodegradation [6]. However, coagulation and precipitation are often too costly, the biodegradation operation is complex, and microorganisms can easily die due to changes in culture conditions [7]. Most dyes are resistant to biodegradation because of their structural complexity [8]. Moreover, biological processes will produce a large amount of sludge, which easily causes new pollution. Catalysis and photocatalysis may also generate new toxic substances, even if they can degrade dyes and fundamentally remove organic pollutants [9]. In contrast, the adsorption method has simple operation, a low cost, and high efficiency and has become one of the most commonly used methods to treat dye wastewater [10]. In recent years, research on the use of agricultural waste to prepare biochar as an adsorbent has gradually increased; example wastes include bamboo [11], crab shell [12], cactus [13], and bagasse [14].

Biomass is the general name for organic matter that is directly
Received October 15, 2020 Accepted May 01, 2021

${ }^{\dagger}$ Corresponding author

E-mail: hulening@126.com

Tel: +0773 3693369

ORCID: 0000-0002-5884-7226 
or indirectly derived from various green plants, such as agricultural waste (chaff, fruit husks, crop straw, etc.), forestry waste (grass, branches, sawdust, etc.), aquatic plants (water hyacinth, algae, etc.), municipal garbage and sewage sludge [15]. Biochar is a type of porous carbon-rich solid material prepared by the pyrolysis of biomass under oxygen-free and anoxic conditions. As a new multifunctional material, biochar is widely used in water pollution control, soil fertility improvement, soil carbon fixation, soil remediation, microbial fuel cell electrodes and other fields [16]. In recent years, biochar prepared from crop straw has attracted much attention due to its outstanding effect. It has large specific surface area, complex pore structure and abundant surface active functional groups, and it has great potential as an adsorbent. However, the physical and chemical properties of biochar largely depend on the type of raw materials and production conditions. Therefore, from the perspective of biochar production, there are two important aspects: selecting the appropriate raw materials and understanding the key production parameters that affect the physical and chemical properties of biochar [17]. In addition, to realize the benefits of biochar in agriculture, it is necessary to design a simple, easy-to-use and economically feasible technology to produce biochar from ordinary biomass waste, which farmers can use to prepare biochar themselves.

Guangxi is the province with the most cassava and banana cultivation in China. Every year, a large amount of cassava and banana straw waste is generated, which causes waste disposal problems. In this paper, cassava and banana straw are used as raw materials, and low-cost and high-adsorption biochars are made by a simple pyrolysis process without further modification and used to adsorb the typical cationic dye MG. This approach can solve the problem of waste disposal. (1) The batch adsorption of MG by banana biochar (BB) and cassava biochar (CB) was studied to analyse the adsorption kinetics, adsorption isotherm, $\mathrm{pH}$ value, and effect of dosage on dye adsorption. (2) Additionally, the physical and chemical properties of $\mathrm{BB}$ and $\mathrm{CB}$ before and after adsorption were studied by characterization to reveal their adsorption mechanism.

\section{Materials and Methods}

\subsection{Materials}

The banana and cassava straws were obtained from the Guilin Qixing Farmers Market, and MG (molecular formula: $\mathrm{C}_{52} \mathrm{H}_{54} \mathrm{~N}_{4} \mathrm{O}_{12}$; structural formula in Fig. 1; $\lambda_{\max }=618 \mathrm{~nm}$ ) was purchased from Guilin Bell Experimental Equipment Co., Ltd. The reagents were of analytical grade.

\subsection{Preparation of $B B$ and $C B$}

The cassava straw was cut into small pieces, simply dried in the sun, placed in an oven to dry at $60-65^{\circ} \mathrm{C}$, ground with a grinder, and passed through a standard sieve of $0.425 \mathrm{~mm}$ to obtain cassava straw powder. The accurately weighed $3 \mathrm{~g}$ of tapioca straw powder was placed in a vacuum/atmosphere tube furnace, the $\mathrm{N}_{2}$ flow rate was set to $500 \mathrm{~mL} / \mathrm{min}$, the heating rate was set to $10^{\circ} \mathrm{C} / \mathrm{min}$, and the sample was kept at $400^{\circ} \mathrm{C}$ for carbonization under anoxic conditions for $2 \mathrm{~h}$. After the furnace was cooled to room temperature, the sample was removed and ground in a crucible. The resulting CB was passed through a $0.425-\mathrm{mm}$ standard sieve and sealed for preservation. Since banana straw contains a large amount of water, water was first removed by a juicer; then, the straw was dried. Subsequent steps were consistent with those for CB preparation, and the resultant product was named BB.

\subsection{Characterization of $B B$ and $C B$}

The surface morphological characteristics of the biochars were observed by scanning electron microscopy (SEM, FEI Inspect F 50 , USA). The surface functional groups of the adsorbents were analysed by Fourier transform infrared spectroscopy (FTIR, Nicolet 380, USA). X-ray diffractometry (XRD, Panalytical, Netherlands) was used to analyse the mineral composition and crystal structure of the biochars. The porosity and specific surface area were determined by Brunauer-Emmett-Teller (BET) method (ASAP24920, USA). Thermogravimetric analysis (TGA, LabSys Evo TG-DTA, TA Q600, USA) was used to determine the stability of the biochars. The element content of the adsorbents was determined by an elemental analyser (Vario EL III, Germany).The TOC content before and after adsorption was determine by TOC analyzer(TOC, $\mathrm{V}_{\mathrm{CPH}}$, Japan)

\subsection{Batch Adsorption Experiments}

The adsorption properties of BB and CB for MG were compared under different conditions, and the adsorption isotherm and adsorption kinetic models were fitted. The details are as follows: different doses of adsorbent were accurately weighed in a 100-mL volumetric flask, and $50 \mathrm{~mL}$ MG solution of different initial concentrations was added. The mixture was oscillated in an oscillator at 150 rpm for different times. After the adsorption was completed, the mixture was filtered with a $0.45-\mu \mathrm{m}$ microporous membrane and analysed with a $722 \mathrm{~S}$ spectrophotometer at a wavelength of 618 $\mathrm{nm}$. The adsorption parameters were as follows: the adsorbent dose was 0.5-3.5 g/L, the initial concentration of MG was 500-1,500 $\mathrm{mg} / \mathrm{L}$ for $\mathrm{BB}$ and $300-800 \mathrm{mg} / \mathrm{L}$ for $\mathrm{CB}$, the oscillation time was 1-1,448 min, and the $\mathrm{pH}$ was 2-8. All experiments were performed at room temperature.

Calculation of the adsorption amount:

$$
Q_{\mathrm{e}}=\left(C_{0}-C_{\mathrm{e}}\right) * V / m
$$

where $Q_{\mathrm{e}}(\mathrm{mg} / \mathrm{g})$ is the biochar adsorption amount; $C_{\mathrm{o}}(\mathrm{mg} / \mathrm{L})$ and $C_{\mathrm{e}}(\mathrm{mg} / \mathrm{L})$ are the concentrations of MG before and after adsorption, respectively; $V(\mathrm{~L})$ is the volume of the adsorption solution; $m$ (g) is the amount of adsorbent.

\section{Results and Discussion}

\subsection{Material Characterization Analysis}

\subsubsection{SEM analysis}

The SEM analysis results of the two biochars before and after adsorption are shown in Fig. 1. Before adsorption, BB has a rough, fibrous cylindrical surface, while CB is in an irregular state. Under 

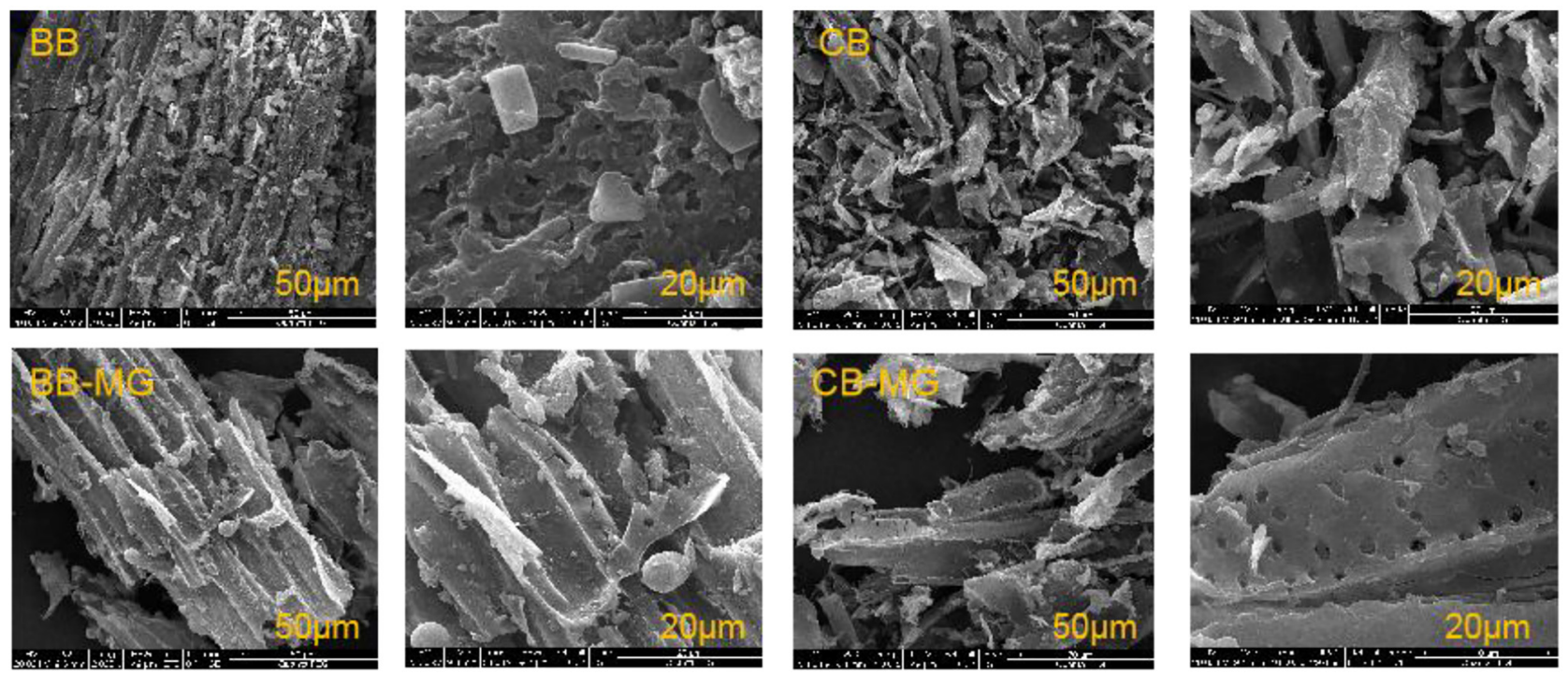

Fig. 1. SEM-EDS analysis of $B B$ and $C B$ before and after $M G$ adsorption.

the carbonization condition of $400^{\circ} \mathrm{C}$, the surface of the two adsorbents becomes rough with irregular random porous shapes due to the elimination of volatile matter. The pore size of BB changes after adsorption, and small balls are generated on the surface, while the inner pore size of CB increases after adsorption, which is consistent with the pore size analysis results. It is speculated that the filling of MG may make the pore diameter smaller and prone to expansion, and the production of pellets may be accompanied by the formation of new substances.

\subsubsection{Element analysis}

Table 1 shows the results of biochar element analysis. The main components of biochar are $\mathrm{C}, \mathrm{H}, \mathrm{N}$ and $\mathrm{O}$. The $\mathrm{H} / \mathrm{C}$ ratio is used to indicate the aromaticity of biochar, $(\mathrm{O}+\mathrm{N}) / \mathrm{C}$ indicates the polarity of biochar, and $\mathrm{O} / \mathrm{C}$ indicates the content of oxygen functional groups in biochar [18]. Comparing the results before and after $\mathrm{BB}$ adsorption, the ratio of $\mathrm{O} / \mathrm{C}$ and $(\mathrm{O}+\mathrm{N}) / \mathrm{C}$ decreases, which indicates that the number of oxygen-containing functional groups in the biochar after adsorption decreases, the hydrophilicity of the biochar surface decreases, and the polarity of the biochar decreases. After the CB adsorption, the hydrophilicity increases, and the oxygen-containing functional groups are almost unchanged. The H/C content of CB and BB increases after adsorption, which indicates that the aromaticity of the two biochars weakened after adsorption. The ratio of $\mathrm{O} / \mathrm{C}$ and $(\mathrm{O}+\mathrm{N}) / \mathrm{C}$ of $\mathrm{BB}$ decreases, which may be caused by a large amount of removal of-OH and-COO in the process of dye adsorption, resulting in the decrease of $\mathrm{O}$ content.
However, the slight increase of $\mathrm{O} / \mathrm{C}$ and $(\mathrm{O}+\mathrm{N}) / \mathrm{C}$ ratios of $\mathrm{CB}$ may be due to irreversible adsorption of dye MG molecules, and the specific surface area and pore volume of CB are obviously larger than those of BB.BB has significantly more oxygen-containing functional groups than CB. It is speculated that the adsorption of CB for MG is mainly based on physical effects and supplemented by chemical effects. The adsorption of BB for MG is mainly due to the chemical adsorption by the oxygen-containing functional groups, followed by physical adsorption. These results also explain the much higher adsorption capacity of BB than that of CB.

\subsubsection{TG-DTG analysis}

Fig. 2 shows the TGA results for the adsorbents. The thermal degradation behaviour of the two biochars was studied between 35-1,00 $5^{\circ} \mathrm{C}$. On the whole, the pyrolysis laws of the two biochars are roughly identical, but BB has faster degradation rate than $\mathrm{CB}$. The TG/DTG curve can be divided into three stages. The first stage $\left(35-200^{\circ} \mathrm{C}\right)$ is caused by the evaporation of water absorbed by BB and $\mathrm{CB}$ as free bound water, which corresponds to DTG weight loss peaks at $67.526^{\circ} \mathrm{C}, 157.32^{\circ} \mathrm{C}$ and $77.407^{\circ} \mathrm{C}$, respectively, The second stage $\left(200-450^{\circ} \mathrm{C}\right)$ is the thermal degradation of cellulose, hemicellulose and other volatile molecules [19]. The third stage $\left(450-1,005^{\circ} \mathrm{C}\right)$ is mainly due to the combustion of residual lignin and the formation of coke. At this temperature, $\mathrm{CO}$ and $\mathrm{CO}_{2}$ may be formed due to the oxidation of non-volatile carbon molecules [20]. The total weight loss of BB and CB is $42.5 \%$ and $42.1 \%$, respectively.

Table 1. Element Analysis Table

\begin{tabular}{lcccccccc}
\hline & $\mathbf{C}(\%)$ & $\mathbf{H}(\%)$ & $\mathbf{N}(\%)$ & $\mathbf{O}(\%)$ & Ash Content(\%) & $\mathbf{H} / \mathbf{C}(\%)$ & $\mathbf{O} / \mathbf{C}(\%)$ & $\mathbf{( O + N ) / C ( \% )}$ \\
\hline CB & 69.52 & 3.412 & 2.26 & 16.248 & 8.56 & 0.049 & 0.234 & 0.266 \\
CB-MG & 73.56 & 3.656 & 2.555 & 18.203 & 2.026 & 0.050 & 0.247 & 0.282 \\
BB & 43.96 & 2.705 & 2.898 & 47.092 & 3.345 & 0.062 & 1.071 & 1.137 \\
BB-MG & 66.685 & 4.37 & 4.336 & 22.803 & 1.806 & 0.066 & 0.342 & 0.407 \\
\hline
\end{tabular}



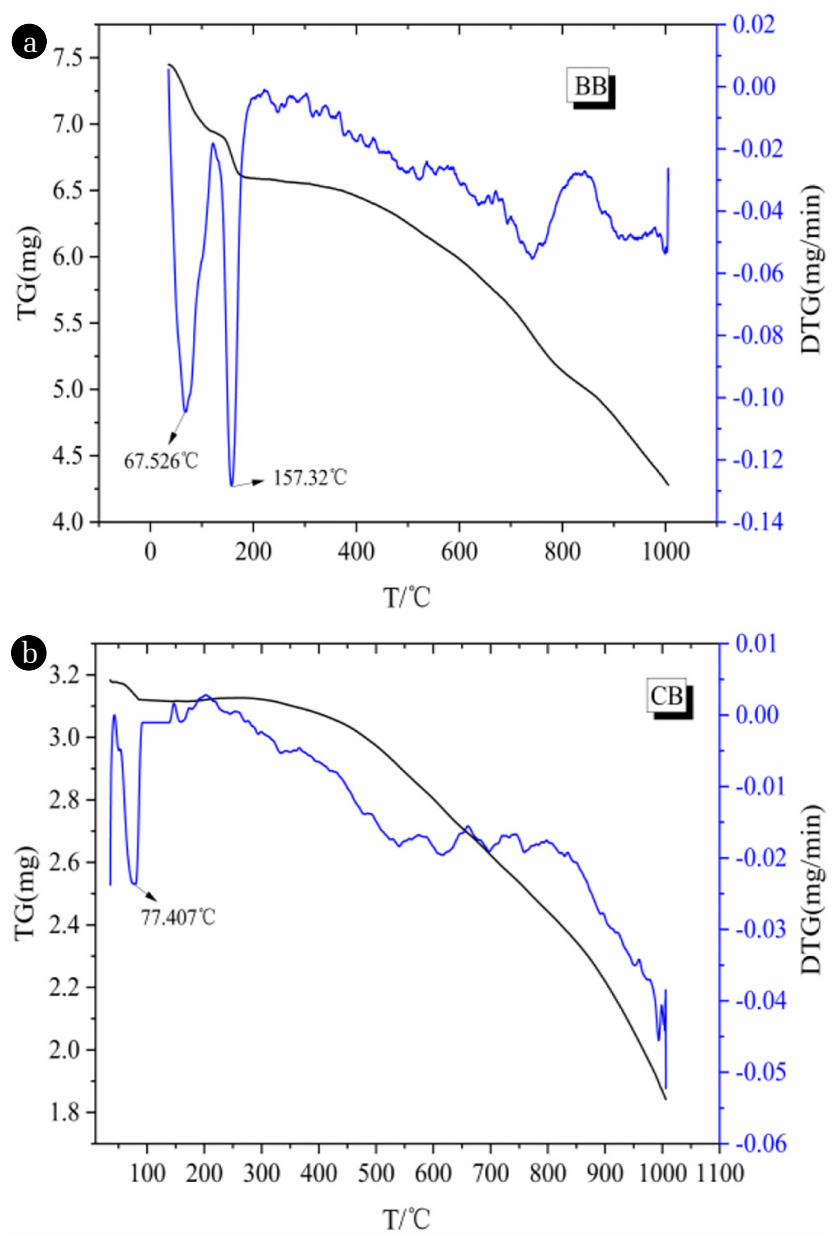

Fig. 2. TG / DTG curves of $\mathrm{BB}$ and $\mathrm{CB}$.

\subsubsection{BET analyses}

Fig. 3 shows four adsorption analysis curves and pore size distribution curves, which correspond to $\mathrm{BB}$ and $\mathrm{CB}$ before and after adsorption. As shown in Table 3, after adsorption, the specific surface area and pore volume of the two biochars decrease, and the pore size doubles. Two reasons are speculated: on one hand, MG fills the pores of the adsorbents due to physical adsorption; on the other hand, the functional groups on the pore surface react with MG to generate new substances. In addition, Fig. 3(b) shows that the pores of $\mathrm{CB}$ and $\mathrm{BB}$ are mainly mesopores of 2-40 $\mathrm{nm}$ [21]. Fig. 3(a) shows the analytical $\mathrm{N}_{2}$ adsorption curves of the two materials before and after adsorption. The $\mathrm{N}_{2}$ adsorption curves belong to type IV. The nitrogen adsorption and desorption curves of all materials are different, and all curves of the four materials show hysteresis. The BB hysteresis band range is $0.5<\mathrm{p} / \mathrm{p}_{0}<1$, the CB hysteresis band range is $0.1<\mathrm{p} / \mathrm{p}_{0}<0.9$, and the hysteresis curves of the two materials are retained after adsorption. The appearance of hysteresis loops is due to the porosity of the materials, which leads to capillary condensation systems. The end of hysteresis indicates that the mesopores of the material are filled, and the adsorption isotherm continues to rise because the adsorbate molecules interact and continue to adsorb to form a multimolecular layer [22].

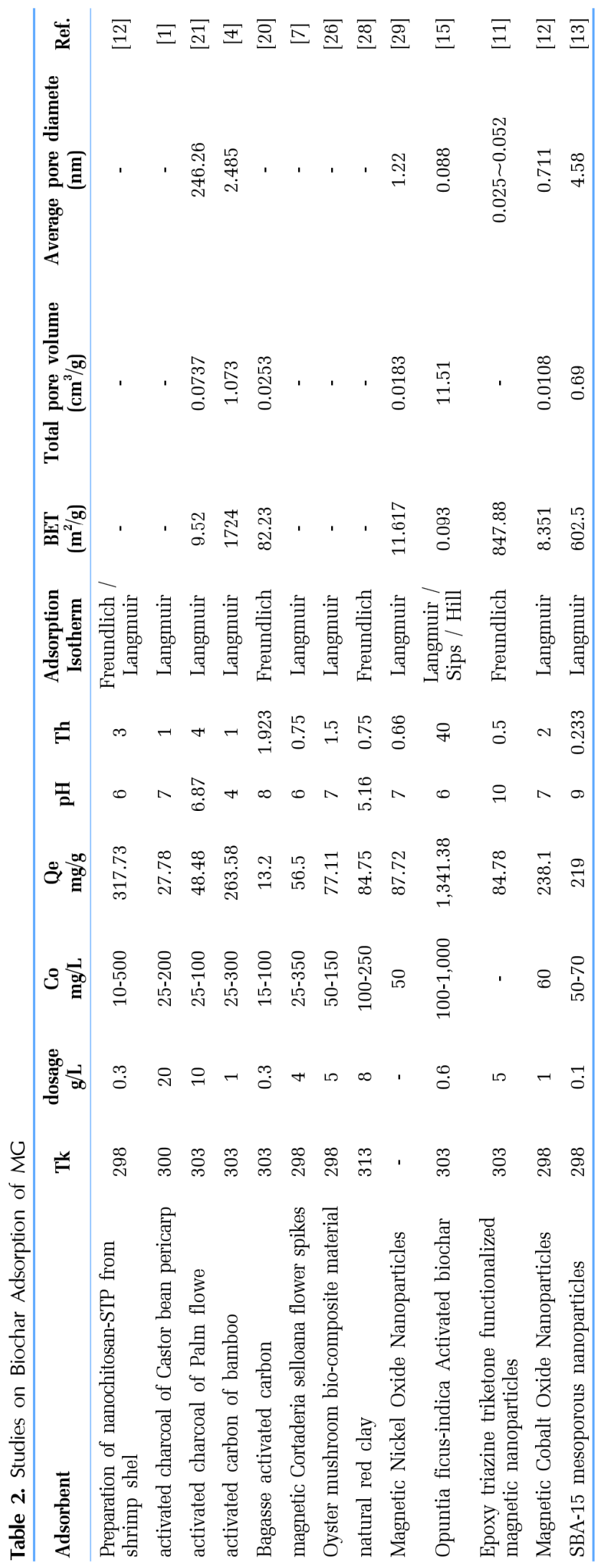




\subsubsection{FTIR analysis}

Fig. 4 shows the infrared spectra of $\mathrm{BB}$ and $\mathrm{CB}$ before and after the MG adsorption. The peaks of $\mathrm{BB}$ and $\mathrm{CB}$ at $2,920 \mathrm{~cm}^{-1}$ and $2,922 \mathrm{~cm}^{-1}$ belong to the strong aliphatic C-H stretching band [23]. The BB and CB peaks at 2,920 $\mathrm{cm}^{-1}$ and $2,922 \mathrm{~cm}^{-1}$ belong to the broad band of hydroxyl $(-\mathrm{OH})$ groups at $3,000-3,500 \mathrm{~cm}^{-1}$

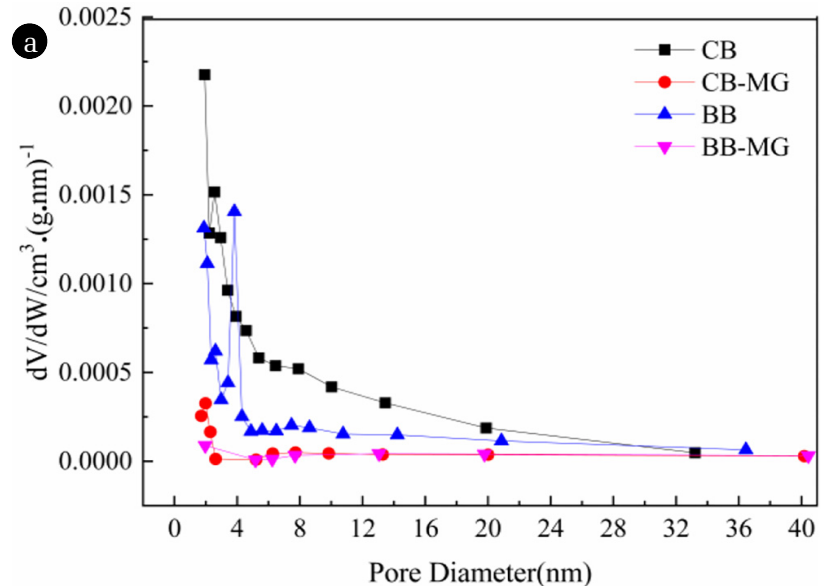

Fig. 3. Biochar daughter-in-law analysis curve.
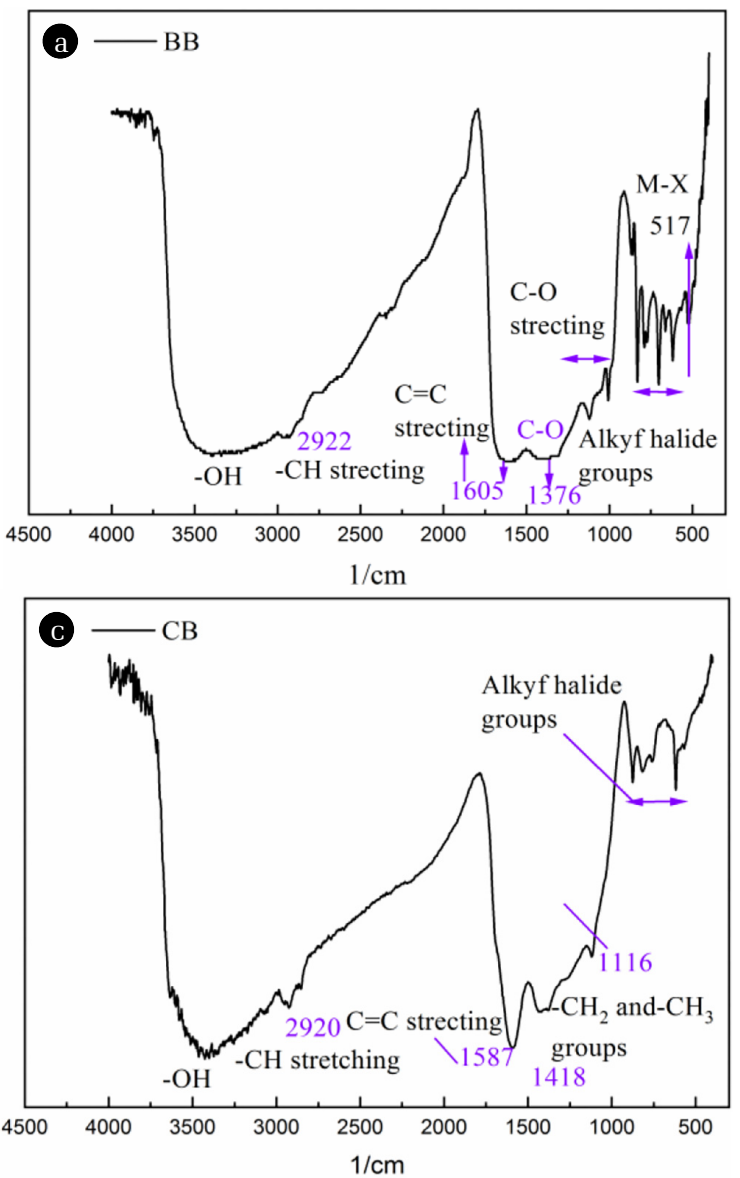

Fig. 4. FTIR spectra before and after $\mathrm{BB}$ and $\mathrm{CB}$ adsorption. and $3,500 \mathrm{~cm}^{-1}$, respectively. After adsorption, the peak value of $\mathrm{BB}$ increases, and the peak value of $\mathrm{CB}$ disappears. The peak at approximately $1,600 \mathrm{~cm}^{-1}$ can be attributed to the stretching vibration of $\mathrm{C}=\mathrm{C}$ bonds in aromatic groups [24] and is characterized by the enhancement and disappearance after adsorption for $\mathrm{CB}$ and $\mathrm{BB}$, respectively. For BB, the peak at 1,000-1,200 $\mathrm{cm}^{-1}$ is attributed to C-O tensile vibrations [25], and the peak
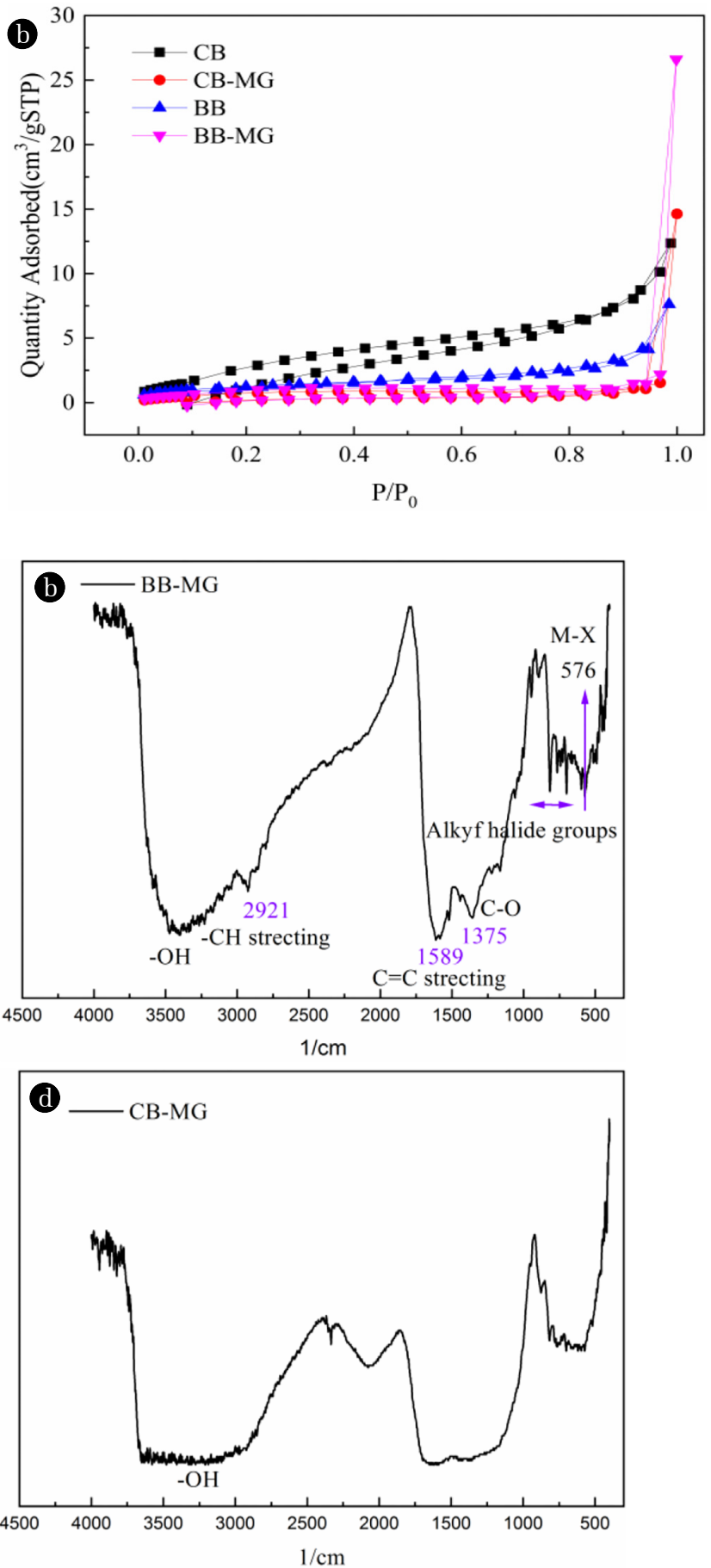
disappears after adsorption. The peak range of $800-600 \mathrm{~cm}^{-1}$ represents the $\mathrm{C}-\mathrm{H}$ rocking vibration of heteroaromatic and aromatic compounds and various alkyl halides [26]. Peaks below $600 \mathrm{~cm}^{-1}$ belong to $\mathrm{M}-\mathrm{X}$ (M: metal; X: halogen) in organic and inorganic halogen compounds, and the peak shift from $517 \mathrm{~cm}^{-1}$ before adsorption to $576 \mathrm{~cm}^{-1}$ after adsorption for BB indicates that BB interacts with the dye organic functional groups after the MG adsorption [27]. The results show that the aromatic structure of the two types of biochar is mainly formed due to the condensation structure of cellulose, hemicellulose, lignin and protein in the biochar during pyrolysis [28]. Moreover, a large number of organic active groups (hydroxyl, carboxyl, carbonyl (-OH, CO, $\mathrm{CH}$ ) and benzene rings) can provide electrons for the dye, and the electrostatic attraction between aromatic hydrocarbons in $\mathrm{BB}$ and $\mathrm{CB}$ and the aromatic structure of MG promotes the dye adsorption by the adsorbents [29].

\subsubsection{XRD analysis}

Fig. 5 shows the XRD analysis results of $\mathrm{BB}$ and $\mathrm{CB}$. The XRD patterns of $\mathrm{BB}$ and $\mathrm{CB}$ before and after adsorption are shown in the figure. The crystal substance corresponding to $\mathrm{BB}$ is $\mathrm{KHCO}_{3}$, which is consistent with the powder diffraction file (PDF) database (PDF card: 73-2155). After adsorption, the crystal structure is destroyed, and a new substance, $\mathrm{C}_{14} \mathrm{H}_{12} \mathrm{O}_{4}$, is formed, which is consistent with the PDF database (PDF card: 50-2270). MG may react with the hydroxyl, carboxyl and carbonyl groups of organic active functional groups in BB to produce new substances [30]. CB has two wide diffraction peaks with no formed crystal structure, which correspond to angles of 42 and 30. After adsorption, the diffraction peaks become smooth, and the overall structure has no obvious change.

\subsubsection{TOC analysis}

The TOC of the solution before and after adsorption was determined by TOC analyzer. The results showed that the TOC content of the original solution was $287.7 \mathrm{mg} / \mathrm{L}$, the TOC content of the solution after BB adsorption was $30.63 \mathrm{mg} / \mathrm{L}$, and the TOC content of the solution after CB adsorption was $63.70 \mathrm{mg} / \mathrm{L}$, which indicated that MG and its derivatives had indeed been removed.

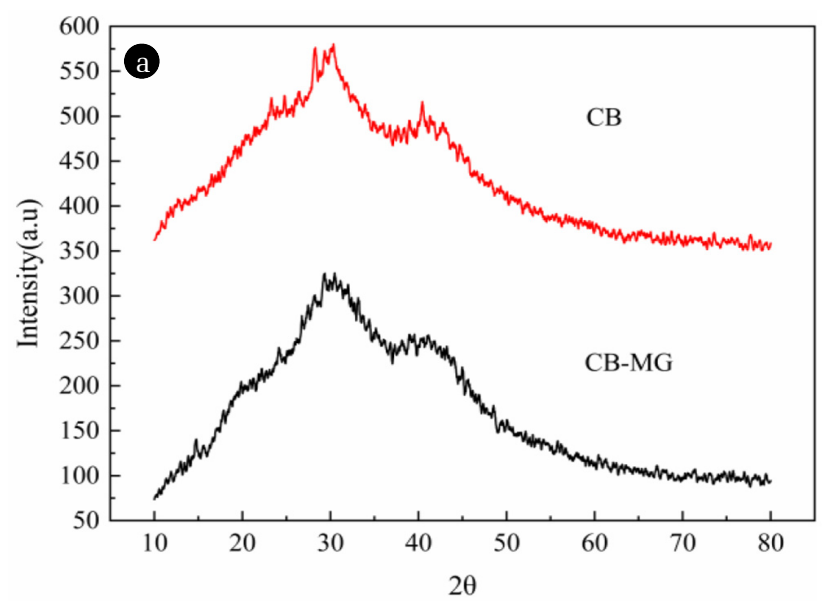

Fig. 5. XRD analysis chart of $\mathrm{BB}$ and $\mathrm{CB}$.

\subsection{Adsorption Experimental Analysis}

\subsubsection{Effect of dosage}

As shown in Fig. S2, when the dosage of the two adsorbents gradually increases from $0.5 \mathrm{~g} / \mathrm{L}$ to $3.5 \mathrm{~g} / \mathrm{L}$, the adsorption amount first increases and subsequently decreases, and the optimal dosage of the two biochars is $2 \mathrm{~g} / \mathrm{L}$. The adsorption amount is limited, and a moderate increase in amount of adsorbent is beneficial to the adsorption of MG by BB and CB. This effect occurs because with the increase in adsorbent dose, the adsorption surface area and number of functional groups in the adsorption increase [31]. Meanwhile, the equilibrium concentration decreases with the increase in addition amount. According to the adsorption equilibrium law, the adsorption capacity decreases.

\subsubsection{Effect of different $\mathrm{pH}$ values}

$\mathrm{pH}$ is one of the main factors that determine the solution adsorption process [32]. Thus, the $\mathrm{pH}$ of the solution greatly affects the surface properties of biochar. The left coordinate axis of Fig. S3 shows the effect of the initial $\mathrm{pH}$ on the adsorption amount. When the $\mathrm{pH}$ increases, the adsorption of $\mathrm{MG}$ by the adsorbents first increases and subsequently stabilizes. At $\mathrm{pH}=5$, the adsorption capacities of $\mathrm{BB}$ to $\mathrm{MG}$ and $\mathrm{CB}$ to $\mathrm{MG}$ were $936.02 \mathrm{mg} / \mathrm{g}$ and $249.91 \mathrm{mg} / \mathrm{g}$, respectively. The right coordinate axis of Fig. 3 shows the $\mathrm{pH}$ change in the solution after adsorption. After adsorption, the $\mathrm{pH}$ of the solution increases relative to the initial $\mathrm{pH}$. The zero charge results show that $\mathrm{BBpzc}=9.84, \mathrm{CBpzc}=10.26$, and the $\mathrm{pHpzc}$ of both biochar is greater than 8 . When $\mathrm{pH}<\mathrm{pHpzc}$, the surface of biochar is positively charged and forms electrostatic repulsion with cationic dye MG, which leads to the inhibition of the adsorption capacity of biochar [33]. Therefore, this may be the reason for the poor adsorption effect of $\mathrm{BB}$ and $\mathrm{CB}$ at low $\mathrm{pH}$. With the increase of $\mathrm{pH}$, the negative charge on the surface of biochar increases, the free $\mathrm{H}^{+}$in the solution gradually decreases, and the electrostatic repulsion weakens, making the MG adsorption effect gradually enhance [34]. However, when the $\mathrm{pH}$ is further increased from 4 to 8 , the adsorption capacity basically tends to be stable without obvious change, indicating that the adsorption mechanism of $\mathrm{BB}$ and CB to MG may have other adsorption mechanisms besides electrostatic adsorption.

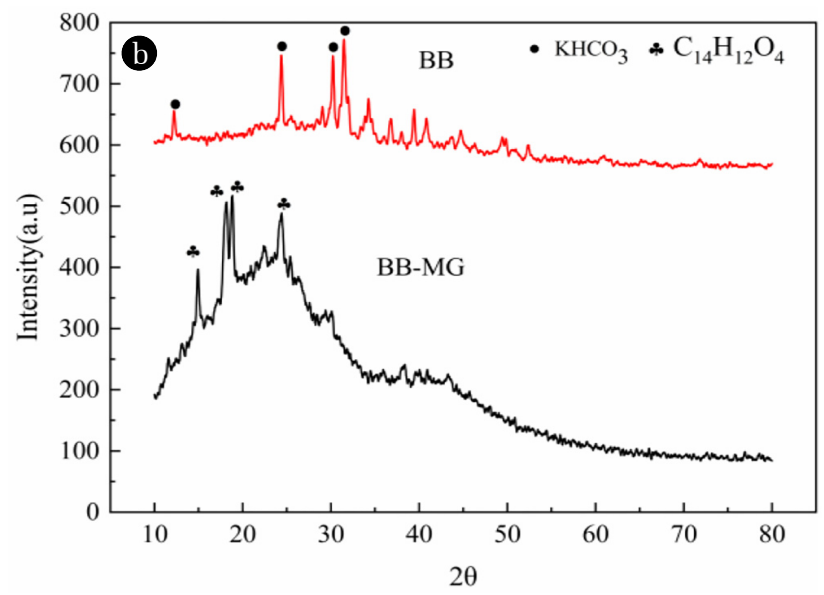




\subsubsection{Adsorption kinetics}

The $\mathrm{pH}$ of the solutions containing $\mathrm{BB}$ and $\mathrm{CB}$ was adjusted to 4 and 5, respectively, to study the effect of different reaction times on the adsorption of MG by the two adsorbents. The results are shown in Fig. S4. At different concentrations, BB adsorbs MG with a fast phase (0-30 $\mathrm{min})$, a medium phase (30-60 $\mathrm{min})$ and a slow phase (60-480 min). CB at a low concentration of $150 \mathrm{mg} / \mathrm{L}$ quickly reaches adsorption equilibrium, and at a concentration of $250 \mathrm{mg} / \mathrm{L}$, CB adsorption of MG can be divided into fast (0-120 min) and slow phases (120-480 min). At a concentration of $500 \mathrm{mg} / \mathrm{L}, \mathrm{CB}$ adsorption of MG can be divided into fast (0-60 min), medium (60-240 min) and slow phases (240-480 min). Thus, both adsorbents can basically reach adsorption equilibrium within $1 \mathrm{~h}$, which exhibits high adsorption efficiency and great practical application potential. However, to ensure that adsorption equilibrium can be reached under all conditions, $4 \mathrm{~h}$ was taken as the adsorption equilibrium reaction time.

Pseudo-first-order kinetics (Eq. (2)) and pseudo-second-order kinetics (Eq. (3)) models were used to fit the experimental data, and intraparticle diffusion was analysed according to Eq. (4).

$$
\begin{gathered}
Q_{\mathrm{t}}=Q_{\mathrm{e}}\left(1-e^{-t K_{t}}\right) \\
Q_{\mathrm{t}}=Q_{\mathrm{e}} t\left(t+1 / k_{2} Q_{\mathrm{e}}\right) \\
Q_{\mathrm{t}}=K_{3} t^{1 / 2}+C
\end{gathered}
$$

where $Q_{\mathrm{t}}(\mathrm{mg} / \mathrm{g})$ is the adsorption amount at time $t ; Q_{\mathrm{e}}(\mathrm{mg} / \mathrm{g})$ is the equilibrium adsorption amount; $t$ ( $\mathrm{min})$ is time; $K(1 / \mathrm{min})$ is the rate constant.

Table S1 presents the fitting results and shows that the pseudo-second-order kinetic correlation coefficient $R^{2}$ is greater than the pseudo-first-order kinetic correlation coefficient under different concentration conditions. This result shows that the pseudo-second-order kinetic model is more consistent with the entire process of MG adsorption by biochar, so the adsorption of MG by $\mathrm{BB}$ and $\mathrm{CB}$ involves both pure physical adsorption and chemical adsorption such as electron transfer and exchange. In addition, BB has significantly smaller $K_{1}$ value than CB, which indicates that $\mathrm{CB}$ has a higher affinity than $\mathrm{BB}$ for negatively charged dyes. The correlation coefficients of the intraparticle diffusion model indicate that there is no linear relationship for the adsorption of MG by BB and CB (the correlation coefficients are 0.6274, $0.7856,0.8610,0.5733,0.7521$, and 0.7779), which shows that the adsorption of MG is not only controlled by intraparticle diffusion. Thus, chemisorption is the rate-controlling step of $\mathrm{BB}$ and $\mathrm{CB}$ adsorption of MG; chemisorption may include the external liquid film diffusion, surface adsorption and intraparticle diffusion [35].

\subsubsection{Adsorption isotherms}

As shown in Fig. S5, the adsorption equilibrium curves of the two adsorbents for MG are slightly different. In this paper, two typical isothermal adsorption models (Langmuir and Freundlich) were used to fit the data to study the distribution of adsorbed molecules in the solid and liquid phases at equilibrium. Eq. (5) and Eq. (6) provide the fitting equations for the two models:

$$
\begin{gathered}
Q_{\mathrm{e}}=K_{\mathrm{F}} C e^{1 / n} \\
Q_{\mathrm{e}}=\frac{C_{\mathrm{e}} K_{\mathrm{L}} Q_{\mathrm{m}}}{1}+K_{\mathrm{L}} C_{\mathrm{e}}
\end{gathered}
$$

where $Q_{\mathrm{e}}(\mathrm{mg} / \mathrm{g})$ is the equilibrium adsorption amount; $C_{\mathrm{e}}(\mathrm{mg} / \mathrm{L})$ is the MG concentration after adsorption; $K_{\mathrm{L}}(\mathrm{L} / \mathrm{mg})$ is Langmuir equilibrium constant; $Q_{\mathrm{m}}(\mathrm{mg} / \mathrm{g})$ is the theoretical saturated adsorption amount; $K_{\mathrm{F}}$ and $n$ are Freundlich constants.

The fitting of the two models at room temperature is shown in Fig. S5, and the resulting fitting parameters are shown in Table S2. The results show that both isotherm models well fit the adsorption process of MG by the two adsorbents. However, the correlation coefficient of the Freundlich model is higher $\left(R^{2}>0.9100\right)$, which shows that the adsorption process of the two biochars is more consistent with Freundlich model, and the interactions between adsorbed molecules involve multilayer adsorption. For both adsorbents, $1 / n<1$, which indicates that MG can be well adsorbed by $\mathrm{BB}$ and $\mathrm{CB}$; the adsorption effect of $\mathrm{BB}$ is better. Comparing $K_{\mathrm{L}}$ and $K_{\mathrm{F}}$ values, we find that $\mathrm{BB}$ has better adsorption and binding stability for MG than CB [36].

Table 2 shows the physical properties and MG adsorption capacity of different adsorbents. In terms of preparation technology, this study is characterized by simple preparation and a low risk of secondary pollution. Although BB and CB have slightly poor physical properties, their adsorption of MG has obvious advantages. As a whole, biochar is an inexpensive and readily available adsorbent material that can provide reference value for the MG wastewater treatment.

\subsection{Adsorption Mechanism}

In this study, the adsorption of MG by the adsorbents BB and CB was studied. The adsorption experiment and characterization results imply that the adsorption mechanism of CB and BB mainly includes chemical adsorption and physical adsorption. The adsorption mechanism is shown in Fig. S1. The physical effect is mainly pore filling. The SEM results and $\mathrm{N}_{2}$ adsorption-desorption isotherms show that $\mathrm{CB}$ and $\mathrm{BB}$ have a hollow structure. By reducing the steric hindrance effect, the physical adsorption capacity of an adsorbent can be increased. Regarding chemical interactions, FTIR and XRD analysis confirm that the biochars have electronic

Table 3. Biochar BET Pore Size and Pore Volume Parameters

\begin{tabular}{lcccc}
\hline Biochar & CB & CB-MG & BB & BB-MG \\
\hline $\mathrm{BET}\left(\mathrm{m}^{2} / \mathrm{g}\right)$ & 13.2564 & 3.0619 & 4.6708 & 3.7749 \\
Average pore diamete $(\mathrm{nm})$ & 5.33087 & 12.7169 & 9.4845 & 18.8421 \\
Total pore volume $\left(\mathrm{cm}^{3} / \mathrm{g}\right)$ & 0.01766 & 0.0097 & 0.01107 & 0.0178 \\
\hline
\end{tabular}


functional groups such as hydroxyl, carboxyl, and carbonyl groups, and these organic active groups can provide $\pi$ electrons to promote the MG adsorption, and $\pi-\pi$ interactions and cation- $\pi$ interactions by the biochar.

\section{Conclusions}

This study proves that banana straw and cassava straw are promising and can be used to produce low-cost biochar to remove MG. The maximum adsorption capacities of the biochars can reach 1,092.80 $\mathrm{mg} / \mathrm{g}$ and $261.42 \mathrm{mg} / \mathrm{g}$, respectively. The characterization analysis shows that $\mathrm{BB}$ and $\mathrm{CB}$ have large specific surface area and pore size, and the biochars are rich in oxygen-containing functional groups. These characteristics provide the biochars with a strong adsorption capacity. Furthermore, the temperature and $\mathrm{pH}$ play an important role in the MG adsorption, which can be due to the electrostatic repulsion between positive charges. Adsorption by the biochars conforms to Freundlich model, and kinetic studies show that the reaction with MG conforms to the pseudo-second-order kinetic model. This technology to convert waste biomass to biochar will be of great significance for maximizing the adsorption of highly toxic textile dyes.

\section{Acknowledgments}

We thank the National Natural Science Foundation of China (No. 41301343) and the State Key Laboratory of Ecology of Endangered Species and Environmental Protection (Guangxi Normal University) (ERESP2019Z07) for their support.

\section{Author Contributions}

D.H. (Professor) and H.LN (Professor) provided research ideas and designed the experiments. L.YF (postgraduate student) conducted the experiments and wrote and revised the manuscript. T.SQ (student) mainly conducted experiments and collected and sorted the data. L.AY (Ph.D. student) read the manuscript and suggested modifications. L.QY (postgraduate student) is responsible for the pretreatment of adsorption materials.

\section{References}

1. Santhi T, Manonmani S, Smitha T. Removal of malachite green from aqueous solution by activated carbon prepared from the epicarp of Ricinus communis by adsorption. J. Hazard. Mater. 2010;179:178-86.

2. Bharti V, Vikrant K, Goswami M, et al. Biodegradation of methylene blue dye in a batch and continuous mode using biochar as packing media. Environ. Res. 2019;171:356-364.

3. Kwapinski W, Kryachko E, Wolfram P, et al. Biochar from biomass and waste. Waste. Biomass. Valor. 2010;1:177-189.

4. Lefebvre L, Agusti G, Bouzeggane A, et al. Adsorption of dye with carbon media supported on polyurethane open cell foam. Catal. Today. 2018;301:98-103.

5. Yakout SM, Hassan MR, Abdeltawab AA, et al. Sono-sorption effificiencies and equilibrium removal of triphenylmethane (crystal violet) dye from aqueous solution by activated charcoal. J. Clean. Prod. 2019;234:124-131.

6. Murray A, Ormeci B. Competitive effects of humic acid and wastewater on adsorption of Methylene Blue dye by activated carbon and non-imprinted polymers. J. Environ. Sci. 2018;66:310-317.

7. Nethaji S, Sivasamy A, Thennarasu G, et al. Adsorption of Malachite Green dye onto activated carbon derived from Borassus aethiopum flower biomass. J. Hazard. Mater. 2010;181:271-280.

8. Zhu B, Cheng H, Qin H, et al. Copper sulfifide as an excellent co-catalyst with $\mathrm{K}_{2} \mathrm{~S}_{2} \mathrm{O}_{8}$ for dye decomposition in advanced oxidation process. Sep. Purif. Technol. 2020;233:116057.

9. Mobeen A, Magdalane M, Lakshmi D, et al. Investigation on antibacterial and photocatalytic degradation of Rhodamine-B dye under visible light irradiation by titanium molybdate nanoparticles prepared via microwave method. Surf. Interface. 2019;17:100381.

10. Dubreil-Chéneau E, Sczubelek L, Burkina V, et al. In vitro investigations of the metabolism of Victoria pure blue $\mathrm{BO}$ dye to identify main metabolites for food control in fish. Chemosphere 2020;238:124538.

11. Nejad SB, Mohammadi A. Epoxy-Triazinetrione-Functionalized Magnetic Nanoparticles as an Efficient Magnetic Nanoadsorbent for the Removal of Malachite Green and $\mathrm{Pb}$ (II) from Aqueous Solutions. J. Chem. Eng. Date. 2020;65:2731-2742.

12. Salamat S, Hadavifar M, Rezaei H. Preparation of nanochitosan-STP from shrimp shell and its application in removing of malachite green from aqueous solutions. J. Environ. Chem. Eng. 2019;7:103328

13. Nethaji S, Sivasamy A. Adsorptive removal of an acid dye by lignocellulosic waste biomass activated carbon: Equilibrium and kinetic studies. Chemosphere 2011;82:1367-1372.

14. Dai LC, Zhu WK, He L, et al. Calcium-rich biochar from crab shell: An unexpected super adsorbent for dye removal. Bioresour. Technol. 2018;267:510-516

15. Choudhary M, Kumar R, Neogi S. Activated biochar derived from Opuntia ficus-indica for the efficient adsorption of malachite green dye, $\mathrm{Cu}(+2)$ and $\mathrm{Ni}(+2)$ from water. J Hazard Mater. 2020;392:122441.

16. Vyavahare GD, Gurav RG, Jadhav PP, Patil RR, Aware CB, Jadhav JP. Response surface methodology optimization for sorption of malachite green dye on sugarcane bagasse biochar and evaluating the residual dye for phyto and cytogenotoxicity. Chemosphere 2018;194:306-315.

17. Ebrahimpour M, Hassaninejad SK, Zavvar MH. Adsorption of ternary toxic crystal violet, malachite green and methylene blue onto synthesised SBA-15 mesoporous nanoparticles. Int. J. Environ. An. Ch. 2020;6:1-24

18. Parlayici S, Pehlivan E. Biosorption of methylene blue and malachite green on biodegradable magnetic Cortaderia selloana flower spikes: modeling and equilibrium study. Int. J. Phytoremediat. 2020;7:1-15. 
19. Mohanta J, Dey B, Dey S. Magnetic Cobalt Oxide Nanoparticles: Sucrose-Assisted Self-Sustained Combustion Synthesis, Characterization, and Efficient Removal of Malachite Green from Water. J. Chem. Eng. Date. 2020;65: 2819-2829.

20. Das L, Das P, Bhowal A, et al. Treatment of malachite green dye containing solution using bio-degradable Sodium alginate $/ \mathrm{NaOH}$ treated activated sugarcane baggsse charcoal beads: Batch, optimization using response surface methodology and continuous fixed bed column study. J. Environ. Manage. 2020;276:111272

21. Kulaksiz E, Gozmen B, Kayan B, Kalderis D. Adsorption of Malachite Green on Fe-modified biochar: influencing factors and process optimization. Desalin. Water. Treat. 2017;74:383-394.

22. Ahmad A, Khan N, Giri BS, Chowdhary P, Chaturvedi P. Removal of methylene blue dye using rice husk, cow dung and sludge biochar: Characterization, application, and kinetic studies. Bioresour. Technol. 2020;306:123202.

23. Shi QQ, Zhang J, Zhang CJ, et al. Preparation of activated carbon from cattail and its application for dyes removal. J. Environ. Sci. 2010;22:91-97.

24. Chang HC, Gustave W, Yuan ZF, Xiao Y, Chen Z. One-step fabrication of binder-free air cathode for microbial fuel cells by using balsa wood biochar. Environ. Technol. Innov. 2020;18: 100615.

25. Nethaji S, Sivasamy A, Thennarasu G, Saravanan S. Adsorption of Malachite Green dye onto activated carbon derived from Borassus aethiopum flower biomass. J. Hazard. Mater. 2010;181: 271-280.

26. Yildirim A. Kinetic, equilibrium and thermodynamic investigations for the bio-sorption of dyes onto crosslinked Pleurotus ostreatus-based bio-composite. Int. J. Environ. An. Ch. 2020;78: 1-16.

27. Keerthanan S, Rajapaksha SM, Trakal L, Vithanage M. Caffeine removal by Gliricidia sepium biochar: Influence of pyrolysis temperature and physicochemical properties. Environ. Res.
2020;189:109865

28. Siruru H, Syafii W, Wistara INJ, Pari G, Budiman I. Properties of sago waste charcoal using hydrothermal and pyrolysis carbonization. Biomass Convers Biorefin. 2020;4:1-12.

29. Sevim F, Lacin O, Ediz EF, Demir F. Adsorption capacity, isotherm, kinetic, and thermodynamic studies on adsorption behavior of malachite green onto natural red clay. Environ. Prog. Sustain. Energy 2020:40(6);13471

30. Mohanta J, Dey B, Dey S. Sucrose-Triggered, Self-Sustained Combustive Synthesis of Magnetic Nickel Oxide Nanoparticles and Efficient Removal of Malachite Green from Water. ACS Omega. 2020;5:16510-16520

31. Chang R, Sohi SP, Jing F, Liu Y, Chen J. A comparative study on biochar properties and Cd adsorption behavior under effects of ageing processes of leaching, acidification and oxidation. Environ. Pollut. 2019;254:113123.

32. Mimmo T, Panzacchi P, Baratieri M, Davies CA, Tonon G. Effect of pyrolysis temperature on miscanthus (Miscanthus $X$ giganteus) biochar physical, chemical and functional properties. Biomass Bioenergy. 2014;62:149-157.

33. Kumar M, Upadhyay SN, Mishra PK. Effect of Montmorillonite clay on pyrolysis of paper mill waste. Bioresour. Technol. 2020;307:123161.

34. Salima A, Benaouda B, Noureddine B, Declaux L. Application of Ulva lactuca and Systoceira stricta algae-based activated carbons to hazardous cationic dyes removal from industrial efflfluents. Water. Res. 2013;47:3375-3388.

35. Santhi T, Manonmani S, Smitha T. Removal of malachite green from aqueous solution by activated carbon prepared from the epicarp of Ricinus communis by adsorption. J. Hazard. Mater. 2010;179:178-186.

36. Saygili H, Guzel F. Performance of new mesoporous carbon sorbent prepared from grape industrial processing wastes for malachite green and Congo red removal. Chem. Eng. Res. Des. 2015;100:27-38. 